\title{
Comparing Luenberger and Luenberger-Hicks-Moorsteen Productivity Indicators: How Well is Total Factor Productivity Approximated? $\dagger$
}

\author{
Kristiaan Kerstens* \\ Zhiyang Shen** \\ Ignace Van de Woestyne*** \\ Initial version: 10 March 2017 \\ Revision: 5 August 2017
}

\begin{abstract}
:
We empirically compare both the popular Luenberger indicator with the less popular Luenberger-Hicks-Moorsteen productivity indicator on an agricultural panel data set of Chinese provinces over the years 1997-2014. In particular, we test for the differences in distribution when comparing these indicators. These tests are crucial to answer the question to which extent the Luenberger indicator can approximate the Luenberger-Hicks-Moorsteen productivity indicator that has a Total Factor Productivity (TFP) interpretation.
\end{abstract}

Keywords: Luenberger indicator, Luenberger-Hicks-Moorsteen indicator, TFP

* CNRS-LEM (UMR 9221), IÉSEG School of Management, 3 rue de la Digue, F-59000 Lille, France. Correspondence to: k.kerstens@ieseg.fr

** China Eximbank, 30 FuXingMenNei Street, 100031 Beijing, China, and IÉSEG School of Management, 3 rue de la Digue, F-59000 Lille, France.

*** Research Unit MEES, KU Leuven, Warmoesberg 26, Brussel B-1000, Belgium

$\dagger$ We thank two referees for providing most constructive comments and help that greatly improved the quality of this contribution. The usual disclaimer applies. 


\section{Introduction}

Total Factor Productivity (TFP) growth is an index number representing technology shifts from output growth that is unexplained by input growth (e.g., Hulten (2001)). Over the last decades, consciousness has developed that ignoring inefficiency may bias TFP measures. Nishimizu and Page (1982) is the seminal article decomposing TFP into a technical change component and a technical efficiency change component.

Caves, Christensen and Diewert (1982) analyze discrete time Malmquist input, output and productivity indices using distance functions as general representations of technology. This index is related to the Törnqvist productivity index that uses both price and quantity information but needs no knowledge on the technology. Färe, Grosskopf, Norris, and Zhang (1994) propose a procedure to estimate the Shephardian distance functions in the Malmquist productivity index by exploiting their inverse relation with the radial efficiency measures computed relative to multiple inputs and outputs nonparametric technologies. They also integrate the two-part Nishimizu and Page (1982) decomposition. The underlying distance functions of this Malmquist productivity index have also been parametrically estimated (e.g., Atkinson, Cornwell and Honerkamp (2003)). Bjurek (1996) proposes a Hicks-Moorsteen TFP index that can be defined as the ratio of a Malmquist output- over a Malmquist input-index. These Malmquist and Hicks-Moorsteen productivity indexes are known to be identical under two strong conditions: (i) inverse homotheticity of technology; and (ii) constant returns to scale (Färe, Grosskopf and Roos (1996)). Therefore, both indices are in general expected to differ, since the conditions needed for their equality are unlikely to be met in empirical work.

While both these primal productivity indices have become relatively popular in empirical work ${ }^{1}$, O’Donnell (2012) convincingly shows that the Malmquist productivity index is not an TFP index that is multiplicatively complete, while there is no such problem for the Hicks-Moorsteen TFP index. Peyrache (2014: p. 435) argues explicitly that the Malmquist productivity index is in fact a "technology index, i.e. a measure of local technical progress (or regress)", which is an argument already found in Grosskopf (2003). The Malmquist productivity index thus measures the displacement of the production frontier at a specific point, but it neglects scale economies. Kerstens and Van de Woestyne (2014) show empirically that the Malmquist productivity index does not offer a good approximation to the Hicks-Moorsteen TFP index in terms of the resulting distributions and that for individual

\footnotetext{
${ }^{1}$ See Färe, Grosskopf and Roos (1998) for an early survey of empirical applications of the Malmquist index.
} 
observations one may well encounter conflicting evidence regarding the basic direction of TFP growth or decline.

More general primal productivity indicators have meanwhile been proposed in the literature. ${ }^{2}$ Chambers, Färe and Grosskopf (1996) introduce the Luenberger productivity indicator as a difference-based index of directional distance functions (see also Chambers (2002)). These directional distance functions generalize the Shephardian distance functions by allowing simultaneous input reductions and output augmentations and they are dual to the profit function. ${ }^{3}$ Briec and Kerstens (2004) define a Luenberger-Hicks-Moorsteen TFP indicator using the same directional distance functions. Though not as popular as the Malmquist productivity index, the Luenberger productivity indicator has recently been used rather widely as a tool for empirical analysis. Examples from a variety of sectors include: agriculture (e.g., Azad and Ancev (2014)), airlines (e.g., Barros and Couto (2013)), banking (e.g., Epure, Kerstens and Prior (2011)), construction (e.g., Kapelko, Horta, Camanho and Oude Lansink (2015)), eco-productivity (e.g., Mahlberg and Sahoo (2011)), energy (e.g., Wang and Wei (2016)), food manufacturing (e.g., Kapelko, Oude Lansink and Stefanou (2015)), petroleum extraction (e.g., Kerstens and Managi (2012)), tourism (e.g., Goncalves (2013)), water (e.g., Molinos-Senante, Maziotis and Sala-Garrido (2014)), among others. ${ }^{4}$ Empirical applications using this Luenberger-Hicks-Moorsteen TFP indicator are rather scant: examples include Ang and Kerstens (2017), Barros, Ibiwoye and Managi (2008), Barros and Managi (2014), and Managi (2010), among others. ${ }^{5}$ Luenberger output (or input) oriented productivity indicators and Luenberger-Hicks-Moorsteen productivity indicators coincide under two demanding properties: (i) inverse translation homotheticity of technology; and (ii) graph translation homotheticity (see Briec and Kerstens (2004) for details). Therefore, one expects both indicators to differ empirically.

\footnotetext{
${ }^{2}$ The distinction between indices and indicators goes back to recent attempts to develop test and economic approaches to index number theory based on differences rather than more traditional ratios (e.g., Diewert (2005)). While economics traditionally works with ratios, business and accounting people are more familiar with analyzing differences (e.g., in terms of cost, revenue or profit). These ratio and difference approaches to index theory differ in terms of basic properties of practical significance: ratios are unit invariant while differences are not; differences are invariant to changes in the origin while ratios are not; ratios cannot cope with zero observations while differences can; etc.

${ }^{3}$ It is possible to define input- and output-oriented versions of this Luenberger indicator that can be interpreted as difference-based versions of the similarly oriented Malmquist productivity indices. Note that the directional distance function does not generalize all existing distance functions: examples include the Hölder distance function (see Briec (1998)) or the weighted additive distance function (see Aparicio, Pastor and Vidal (2016)).

${ }^{4}$ A Google Scholar search on 4 March 2017 obtained 982 results for the expression "Luenberger productivity". By contrast, the expression "Malmquist productivity" yields 9240 hits.

${ }^{5}$ A Google Scholar search on 4 March 2017 obtained just 61 results for the expression "Luenberger-HicksMoorsteen productivity". By contrast, the expression "Hicks-Moorsteen productivity" yields 198 results.
} 
The claims of O'Donnell (2012) regarding the Malmquist productivity index can also be transposed to the Luenberger productivity indicator. Equally so, Peyrache (2014: p. 441) argues explicitly that the same holds true for indicators: thus, the Luenberger indicator measures TFP in an incomplete way because it neglects scale economies. Nevertheless, one often finds claims in the literature that the Luenberger productivity indicator measures total factor productivity (e.g., Molinos-Senante, Maziotis and Sala-Garrido (2014: p. 19)). However, to the best of our knowledge, no study ever empirically verified whether the Luenberger productivity indicator offers a good empirical approximation to the Luenberger-HicksMoorsteen TFP indicator. This is the basic question we set out to answer in this contribution.

This paper is structured as follows. Section 2 formally introduces the Luenberger productivity indicator as well as the Luenberger-Hicks-Moorsteen TFP indicator. Thereafter, the necessary nonparametric frontier specifications are developed. Section 3 introduces the agricultural panel data set of Chinese provinces. Thereafter, it presents the empirical results in detail. A final section concludes.

\section{Methodology}

\subsection{Technology and Distance Functions}

We first review the assumptions on technology and the definitions of the distance functions providing the components for computing the productivity indicators. Assume that decision making units (DMUs) have $N$ number of inputs $(x)$ that can be used to produce $M$ number of outputs $(y)$. The classical production possibility set for each time period $t$ can be defined as follows:

$$
T(t)=\left\{\left(x^{t}, y^{t}\right) \in \mathbb{R}_{+}^{N+M} ; \quad x^{t} \text { can produce } y^{t}\right\}
$$

Throughout this paper, this technology satisfies the following conventional assumptions: no free lunch, closedness, and strong input and output disposability. Occasionally, stronger assumptions (e.g., convexity or nonconvexity) are needed (see Hackman (2008) for details).

Efficiency is estimated relative to production frontiers using distance or gauge functions. The directional distance function $D_{T(t)}(., . ; g): \mathbb{R}_{+}^{N+M} \rightarrow \mathbb{R}$ involving a 
simultaneous input and output variation in the direction of a pre-assigned vector $g=\left(g_{x}, g_{y}\right) \in \mathbb{R}_{+}^{N+M}$ is defined as:

$$
D_{T(t)}\left(x, y ; g_{x}, g_{y}\right)=\max _{\theta}\left\{\theta ;\left(x-\theta g_{x}, y+\theta g_{y}\right) \in T(t)\right\}
$$

This directional distance function (Chambers, Färe and Grosskopf (1996)) is a special case of the shortage function (Luenberger (1992)) ${ }^{6}$ and measures the gap between the observed production plans and the production frontier defined by the best practices. The inefficiency score $\theta$ represents the maximum possible simultaneous increase in outputs and decrease in inputs.

\subsection{Productivity Indicators: Definitions}

In the general case of directional distance functions, the Luenberger productivity indicator $L\left(\left(x^{t}, y^{t}\right),\left(x^{t+1}, y^{t+1}\right) ; g^{t}, g^{t+1}\right)$ is defined by Chambers (2002) as follows:

$$
\begin{aligned}
& L\left(\left(x^{t}, y^{t}\right),\left(x^{t+1}, y^{t+1}\right) ; g^{t}, g^{t+1}\right)= \\
& \frac{1}{2}\left[\left(D_{T(t)}\left(x^{t}, y^{t} ; g^{t}\right)-D_{T(t)}\left(x^{t+1}, y^{t+1} ; g^{t+1}\right)\right)+\left(D_{T(t+1)}\left(x^{t}, y^{t} ; g^{t}\right)-D_{T(t+1)}\left(x^{t+1}, y^{t+1} g^{t+1}\right)\right)\right] .
\end{aligned}
$$

When $g^{t}=\left(x^{t}, y^{t}\right)$ and $g^{t+1}=\left(x^{t+1}, y^{t+1}\right)$ are the direction vectors over time, then one obtains a proportional indicator, as first mentioned in Chambers, Färe and Grosskopf (1996). To avoid an arbitrary choice of base years, the arithmetic mean of a difference-based Luenberger productivity indicator in base year $t$ (first difference) and $t+1$ (second difference) is taken. Productivity growth (decline) shows up by positive (negative) values.

Extending some basic elements developed in Chambers (1998, 2002), Briec and Kerstens (2004) define a Luenberger-Hicks-Moorsteen TFP indicator with base period $t$ $L H M_{T(t)}\left(x^{t+1}, y^{t+1}, x^{t}, y^{\mathrm{t}} ; g^{t}, g^{t+1}\right)$ as the difference between a Luenberger output quantity indicator $L O_{T(t)}\left(x^{\mathrm{t}}, y^{\mathrm{t}}, y^{\mathrm{t}+1} ; g_{y}^{t}, g_{y}^{t+1}\right)$ and a Luenberger input quantity indicator $L I_{T(t)}\left(x^{\mathrm{t}}, y^{\mathrm{t}}, y^{\mathrm{t}+1} ; g_{y}^{t}, g_{y}^{t+1}\right)$ :

\footnotetext{
${ }^{6}$ Note that this function is defined using a general directional vector $g$, while we consider the special case: $g_{x}=x$ and $g_{y}=y$. The distance function with the latter choice is also known as the Farrell proportional distance function (see Briec (1997)).
} 


$$
\begin{aligned}
& L H M_{T(t)}\left(x^{\mathrm{t}+1}, y^{\mathrm{t}+1}, x^{\mathrm{t}}, y^{\mathrm{t}} ; g^{t}, g^{t+1}\right) \\
& =\left(D_{T(t)}\left(x^{\mathrm{t}}, y^{\mathrm{t}} ; 0, g_{y}^{t}\right)-D_{T(t)}\left(x^{\mathrm{t}}, y^{\mathrm{t}+1} ; 0, g_{y}^{t+1}\right)\right)-\left(D_{T(t)}\left(x^{\mathrm{t}+1}, y^{\mathrm{t}} ; g_{x}^{t+1}, 0\right)-D_{T(t)}\left(x^{\mathrm{t}}, y^{\mathrm{t}} ; g_{x}^{t}, 0\right)\right) \\
& \equiv L O_{T(t)}\left(x^{\mathrm{t}}, y^{\mathrm{t}}, y^{\mathrm{t}+1} ; g_{y}^{t}, g_{y}^{t+1}\right)-L I_{T(t)}\left(x^{\mathrm{t}}, x^{\mathrm{t}+1}, y^{\mathrm{t}} ; g_{x}^{t}, g_{x}^{t+1}\right) .
\end{aligned}
$$

When this indicator is larger (smaller) than zero, it indicates productivity gain (loss). A Luenberger-Hicks-Moorsteen productivity indicator with base period $t+1$ can be defined:

$$
\begin{aligned}
& L H M_{T(t+1)}\left(x^{t+1}, y^{t+1}, x^{\mathrm{t}}, y^{\mathrm{t}} ; g^{t}, g^{t+1}\right) \\
& =\left(D_{T(t+1)}\left(x^{t+1}, y^{\mathrm{t}} ; 0, g_{y}^{t}\right)-D_{T(t+1)}\left(x^{t+1}, y^{t+1} ; 0, g_{y}^{t+1}\right)\right)-\left(D_{T(t+1)}\left(x^{t+1}, y^{t+1} ; g_{x}^{t+1}, 0\right)-D_{T(t+1)}\left(x^{\mathrm{t}}, y^{t+1} ; g_{x}^{t}, 0\right)\right) \\
& \equiv L O_{T(t+1)}\left(x^{t+1}, y^{t+1}, y^{\mathrm{t}} ; g_{y}^{t}, g_{y}^{t+1}\right)-L I_{T(t+1)}\left(x^{\mathrm{t}}, x^{t+1}, y^{t+1} ; g_{x}^{t}, g_{x}^{t+1}\right) .
\end{aligned}
$$

The arithmetic mean of these two base periods Luenberger-Hicks-Moorsteen TFP indicators yields:

$$
\begin{aligned}
& \operatorname{LHM}_{T(t), T(t+1)}\left(x^{\mathrm{t}}, y^{\mathrm{t}}, x^{\mathrm{t}+1}, y^{\mathrm{t}+1} ; g^{t}, g^{t+1}\right) \\
& =\frac{1}{2}\left[L H M_{T(t)}\left(x^{\mathrm{t}}, y^{\mathrm{t}}, x^{\mathrm{t}+1}, y^{\mathrm{t}+1} ; g^{t}, g^{t+1}\right)+L H M_{T(t+1)}\left(x^{\mathrm{t}}, y^{\mathrm{t}}, x^{\mathrm{t}+1}, y^{\mathrm{t}+1} ; g^{t}, g^{t+1}\right)\right] .
\end{aligned}
$$

Again, productivity growth (decline) is signaled by positive (negative) values.

Just as the Malmquist productivity index, the Luenberger productivity indicator may yield infeasible solutions (Briec and Kerstens (2009b)). By contrast, just as the HicksMoorsteen productivity index (see Briec and Kerstens (2011)), the Luenberger-HicksMoorsteen TFP indicator is normally always determinate and infeasibilities should not occur under weak conditions on technology.

Observe that both productivity indicators differ substantially in terms of computational complexity: while the Luenberger productivity indicator requires the computation of four directional distance functions, the Luenberger-Hicks-Moorsteen indicator necessitates computing eight different directional distance functions per evaluated observation.

As stressed in Hulten (2001), though the concept of TFP does not presume constant returns to scale, a lot of empirical productivity studies in fact impose constant returns to scale. Therefore, in the empirical specifications of technologies that follow in the next subsection we will allow for both constant and variable returns to scale. 


\section{3. Model Specification for Technologies}

The empirical study conducted for this research is based on nonparametric technologies. Two returns to scale types, i.e., constant (CRS) and variable returns to scale (VRS) are combined with two shape types, i.e., convexity (C) and nonconvexity (NC) realizing four different technologies. Consider the availability at time $t$ of $K$ observations $\left(x_{1,1}^{t}, \ldots, x_{1, N}^{t} ; y_{1,1}^{t}, \ldots, y_{1, M}^{t}\right), \ldots,\left(x_{K, 1}^{t}, \ldots, x_{K, N}^{t} ; y_{K, 1}^{t}, \ldots, y_{K, M}^{t}\right) \in \mathbb{R}_{+}^{N+M}$. Then, using the unified algebraic approach of Briec, Kerstens and Vanden Eeckaut (2004), technology can be represented by

$$
\begin{aligned}
T^{\Lambda, \Gamma}(t)= & \left\{(x, y) \in \mathbb{R}_{+}^{N+M}: \sum_{k=1}^{K} \delta z_{k} y_{k, i}^{t} \geq y_{i},(i=1, \ldots, N),\right. \\
& \left.\sum_{k=1}^{K} \delta z_{k} x_{k, j}^{t} \leq x_{j},(j=1, \ldots, M), z \in \Lambda, \delta \in \Gamma\right\},
\end{aligned}
$$

with $\Lambda=\left\{z \in \mathbb{R}^{K}: \sum_{k=1}^{K} z_{k}=1, z_{k} \in \mathbb{R}_{+},(k=1, \ldots, K)\right\} \quad$ if $\quad$ convexity $\quad$ is assumed and $\Lambda=\left\{z \in \mathbb{R}^{K}: \sum_{k=1}^{K} z_{k}=1, z_{k} \in\{0,1\},(k=1, \ldots, K)\right\}$ in the case of nonconvexity, and $\Gamma=\mathbb{R}_{+}$in case of CRS and $\Gamma=\{1\}$ if VRS is imposed.

Computing the directional distance function (2) relative this general technology (7) boils down to solving the following nonlinear problem:

$$
\begin{aligned}
D_{T(t)}\left(x, y ; g_{x}, g_{y}\right)=\max _{\theta}\left\{\theta: \sum_{k=1}^{K} \delta z_{k} y_{k, i}^{t} \geq y_{i}+\theta g_{y},(i=1, \ldots, N),\right. \\
\left.\sum_{k=1}^{K} \delta z_{k} x_{k, j}^{t} \leq x_{j}-\theta g_{x},(j=1, \ldots, M), \sum_{k=1}^{K} z_{k}=1, z \in \Lambda, \delta \in \Gamma\right\},
\end{aligned}
$$

In the convex case, transformation of (8) to a linear problem (LP) can easily be realized. If nonconvexity is assumed, then nonlinear mixed binary programs need to be solved. Alternatively, the LP models provided by Leleu (2009) can be used, or the enumeration method of Cherchye, Kuosmanen and Post (2001) in the VRS case.

When examining the Luenberger productivity indicator (3) in greater detail, note that observation $\left(x^{t+1}, y^{t+1}\right)$ is compared with respect to technology $T(t)$ in the first difference, while observation $\left(x^{t}, y^{t}\right)$ is compared with respect to technology $T(t+1)$ in the second 
difference. Hence, obtaining the Luenberger indicator involves computing the directional distance function for observations that can be located outside the current technology. If feasible, corresponding directional distance function values will be negative. But then, some of the output related constraints in (8) (i.e., $\sum_{k=1}^{K} \delta z_{k} y_{k, i}^{t} \geq y_{i}+\theta g_{y},(i=1, \ldots, N)$ ) may lead to negative outputs. Since negative output levels make no sense in a normal production context, Briec and Kerstens (2009a) suggest adding the positivity constraints $y_{i}+\theta g_{y} \geq 0,(i=1, \ldots, N)$ to the specifications of (8).

\section{Empirical Analysis}

\subsection{Chinese Agricultural Data}

We use a balanced panel of agricultural data from 31 Chinese mainland provinces over the years 1997-2014. These provinces can be grouped in three large economic zones: the eastern region (with 11 relatively rich provinces: Beijing, Tianjin, Hebei, Liaoning, Shanghai, Jiangsu, Zhejiang, Fujian, Shandong, Guangdong, and Hainan), the inland region (with 8 provinces: Shanxi, Jilin, Heilongjiang, Anhui, Jiangxi, Henan, Hubei, and Hunan), and the western region (with 12 relatively backward provinces: Inner Mongolia, Guangxi, Sichuan, Chongqing, Guizhou, Yunnan, Tibet, Shannxi, Gansu, Qinhai, Ningxia, and Xinjiang). This ignores the regions of Hong Kong, Macao and Taiwan in China.

The agricultural technology is defined with five inputs: agricultural labor, machinery, land, pesticide, and fertilizer (containing nitrogen, phosphate, potash, and compound fertilizers). These five inputs are measured by the number of rural employed persons, the total power of agricultural machinery, the total sown areas of farm crops, the use of pesticide, and volume of fertilizer respectively. The single output is the gross agricultural output value that is depreciated at the 2010 price level. The data is collected from the China Statistical Yearbook, China Rural Statistical Yearbook, and China Statistical Yearbook for Regional Economy (National Bureau of Statistics of China, 1998-2015).

The above specification of output and inputs is in line with the rather limited literature on Chinese agricultural analysis at the provincial level. For example, Ito (2010) analyzes differences of Chinese agricultural TFP across regions using the value of agricultural production as output, and agricultural labor, fertilizer, electricity consumption, machinery, 
and irrigation rate as inputs. We rather closely follow his approach, but following Chen et al. (2008) we employ sown areas (in quantity) instead of the irrigation rate (percentage). ${ }^{7}$ Furthermore, since electricity consumption and machinery are strongly correlated and both capture the energy aspect of agriculture, we only use the latter. Finally, we also add pesticide as an input.

The basic descriptive statistics of inputs and output are shown in Table 1. In particular, the standard deviations show that the sample reflects the wide-ranging diversity among Chinese provinces. This variation in the size of the agricultural sector is taken into account in our activity analysis framework, because we use both constant and variable returns to scale models that allow for size differences between observations. Furthermore, one can also notice that the annual growth rate of gross output value (average trend $4.1 \%$ ) in the Chinese agricultural sector seems mainly due to the increase in the use of machinery, pesticide, and fertilizer, while the inputs of land and labor experience an almost constant trend.

$<$ Table 1 about here $>$

\subsection{Empirical Results}

Firstly, the cumulative Luenberger and Luenberger-Hicks-Moorsteen productivity indicators for the whole of China are plotted in Figure 1 over time for a total of eight scenarios: convex and nonconvex technologies, and CRS and VRS technologies, respectively. Three clusters of productivity growth can be identified in Figure 1. A first group includes the Luenberger-Hicks-Moorsteen productivity indicators under Convex-CRS, Convex-VRS, and Nonconvex-CRS technologies that measure the highest cumulative growth. The second set containing Luenberger-Hicks-Moorsteen productivity indicators under Nonconvex-VRS technology, Luenberger productivity indicators under Convex-CRS, Convex-VRS, and Nonconvex-CRS technologies that all indicate a very similar trend and a moderate cumulative growth. The third cluster is the Luenberger productivity indicator under a Nonconvex-VRS technology which is the only one to display a negative trend. Therefore, when a NonconvexVRS technology is assumed, the two productivity indicators both seem significantly different from the other indicators and the productivity growth rates are lower than for the other combinations of assumptions.

\footnotetext{
${ }^{7}$ Note furthermore that ratios cause some interpretational problems when adopting a nonparametric framework.
} 
The following preliminary conclusions can be drawn. First, for any given specific technology, the absolute value of the Luenberger indicator is smaller than that of its Luenberger-Hicks-Moorsteen counterpart. This confirms the earlier interpretation that the Luenberger is a technology indicator that only captures TFP in an incomplete way: hence, the gap between both indicators. This also confirms the empirical results reported in Barros et al. (2008), the only (unpublished) study comparing both indicators we are aware of. Second, the stronger the assumptions maintained on the technology, the higher the cumulative productivity growth: convexity leads to higher growth than nonconvexity, just as CRS yields higher growth compared to VRS. Barros et al. (2008) confirm the same tendency when comparing CRS and VRS results.

We then present the annual average Luenberger and Luenberger-Hicks-Moorsteen productivity changes among 31 provinces in Table 2 . We can observe that there are substantial differences among Luenberger and Luenberger-Hicks-Moorsteen productivity changes related to the precise assumptions imposed on the production technology. Three observations stand out. First, the average Luenberger-Hicks-Moorsteen productivity changes are larger than the average Luenberger productivity variations. Second, while most yearly average productivity changes are positive, a negative annual average productivity change (0.0113) is detected for the Luenberger indicator under nonconvex and VRS technology.

Third, an analysis of contradictory results as reported by the opposite sign of each productivity indicator under the same assumptions on production technology yields the following results. Opposite signs between Luenberger and Luenberger-Hicks-Moorsteen indicators occur most when a nonconvex VRS technology is assumed: at least 18 out of 31 provinces show an opposing trend of productivity evolution in some of the years. Opposite signs occur the least under a convex CRS technology: there are at only 2 out of 31 provinces revealing a conflicting development between the two productivity indicators. These contradictory results are very similar to the ones reported in Kerstens and Van de Woestyne (2014) comparing Malmquist and Hicks-Moorsteen indices.

Fourth, as demonstrated by Briec and Kerstens (2009b) the Luenberger productivity indicator may well lack determinateness because of infeasible linear programs for the crossperiod distance functions. In our sample, we find no such infeasibilities at all in the sample. The reader can consult Kerstens and Van de Woestyne (2014) for reports on infeasibilities in 
computing the Malmquist index for balanced and unbalanced panel data, as well as for further references in the literature reporting positive amounts of infeasibilities. By contrast, the Luenberger-Hicks-Moorsteen indicator is determinate by definition (as proven in Briec and Kerstens (2011: p. 774) by implication).

Fifth, when computing the Luenberger productivity indicator we observe no impact at all on any observation of imposing the above mentioned positivity constraints on the specifications of (8). In the literature, Juo, Fu, Yu and Lin (2016: p. 216) are the only other study we are aware of that explicitly tested for the impact of these positivity constraints: they also report no effect on their sample. ${ }^{8}$

\section{$<$ Table 2 about here $>$}

We formally test for the differences between the densities resulting from these different productivity indicators with a test statistic defined by Li (1996) and refined by Fan and Ullah (1999) that is valid for both dependent and independent variables. Note that dependency is a characteristic of the nonparametric frontier estimators used for computing the directional distance functions (for instance, efficiency levels depend on sample size, among others). The null hypothesis of this test statistic is that the distributions of both productivity indicators are equal for a given specification of technology. The alternative hypothesis is simply that both distributions are different. In addition, we compute the Kullback-Leibler (KL) divergence, which is a distance (but not a metric) between two density functions (see Karian and Dudewicz (2010: p. 327)). In general, the smaller the KL distance, the closer the target density function is to the true density function. In this study, we just compare two empirical Gaussian kernel density estimations obtained from the computed productivity indicators. Since the KL divergence fails symmetry, we report two distance values for these densities: first the smallest, then the largest. ${ }^{9}$

Furthermore, even though the distributions may be rather similar, the relative order of Chinese provinces may have changed. To control for the effects on the relative order of provinces, we report first Spearman rank correlation coefficients. Finally, to assess the rank correlations in a more robust fashion, we report results based on isotonic regression (see, e.g.,

\footnotetext{
${ }^{8}$ In a preliminary round, we experimented with a specification of 7 instead of 5 inputs (adding information on the use of plastic film and energy consumption): this specification leads to infeasibilities for a few observations.

${ }^{9}$ In principle, it is also possible to condition the above tests on a series of contextual variables. Examples include eastern vs. western vs. inland provinces, percentage rice in total crop, etc. This would lead to condition a given productivity indicator on such a variable. This would allow to contrast Luenberger versus LHM indicators on reduced sample sizes only. Therefore, we intend to keep this for eventual future work.
} 
Silvapulle and Sen (2005)). Isotonic regression involves finding a weighted least-squares fit subject to a series of order restrictions. This isotonicity constraint realizes a nondecreasing piecewise linear graph having more flexibility to follow the data compared to the regression line.

From Table 3, we can see that for any of the four specifications of technology the Litest statistic clearly rejects the null hypothesis that the Luenberger indicator and the Luenberger-Hicks-Moorsteen indicator follow the same distribution as estimated by kernel densities. This obviously confirms the graphical cumulative results displayed in Figure 1. This is a key result of our empirical investigation: the Luenberger productivity indicator does not yield a good approximation of the Luenberger-Hicks-Moorsteen productivity indicator that has a TFP interpretation. The KL divergence basically confirms these results: the magnitude of the KL divergence rises almost monotonically with the magnitude of the Li-test statistic.

The Spearman rank correlation coefficients reported in Table 3 are all significantly different from zero and allow to conclude the following. First, the CRS indicators correlate higher than the VRS indicators for given convexity/nonconvexity assumption. Second, nonconvex indicators correlate better for CRS, while convex indicators correlate better for VRS.

\section{$<$ Table 3 about here $>$}

To observe more details over the years, in Table 4 we illustrate the Luenberger and Luenberger-Hicks-Moorsteen productivity indicators over time under a typical scenario: convex and VRS technology. These detailed results allow to conclude the following. First, the average Luenberger indicator is always smaller than the average Luenberger-HicksMoorsteen in absolute value. Second, the signs of average Luenberger and Luenberger-HicksMoorsteen indicators agree over the years, except for the year 2004-2005 when the sign is opposite. Third, the standard deviation as well as the range of the Luenberger indicator is smaller than that of the Luenberger-Hicks-Moorsteen. Finally, there are several years with only 1 out of 31 provinces showing opposing results, but at most 8 out of 31 provinces reveal contradictory results during the years 2007-2008. This is consistent with the results in Table 2 and suggests that the productivity growth estimated by Luenberger and Luenberger-HicksMoorsteen productivity indicators seems to show significant differences even though some of the cumulative growth paths appear very similar in Figure 1.

$<$ Table 4 about here $>$ 
We further explore the eventual differential impact of the specifications of the technology on the Luenberger and Luenberger-Hicks-Moorsteen indicators. Table 3 reports several $\mathrm{Li}$ (1996) test statistics related to the various specifications of technology. ${ }^{10}$ The upper part of Table 4 tests for CRS versus VRS for a given indicator with or without convexity. Only for the Luenberger indicator under convexity we cannot reject the null hypothesis that CRS and VRS productivity distributions are identical. Otherwise, CRS and VRS productivity distributions are different. The lower part of Table 4 tests for convexity versus nonconvexity for a given indicator with CRS or VRS. Only for the Luenberger indicator under CRS we cannot reject the null hypothesis that convex and nonconvex productivity distributions are equal. Otherwise, convex and nonconvex productivity distributions are different, albeit only marginally so for the Luenberger-Hicks-Moorsteen indicator under CRS. Again, the KL divergence reported in Table 3 corroborates these results in that its magnitude almost monotonically increases with the Li-test statistic.

Also in Table 3, an analysis of the Spearman rank correlations (all significantly different from zero) yields the following conclusions. For a given specification, (i) LHM obtains higher correlations than the Luenberger indicator, (ii) convexity has higher correlations compared to nonconvexity, and (iii) CRS yields higher correlations than the VRS specification. For the isotonic regression results, for reasons of space we limit ourselves to two figures only. Both Figures 2 and 3 depict the case of the LHM indicator and contrast CRS versus VRS results. Figure 2 depicts the convex case, while Figure 3 reveals the nonconvex case. While the ranks near the middle have a very good fit in both cases, the ranks near the extremes seem to have a better fit under nonconvexity compared to convexity. This more detailed picture therefore allows to go beyond the Spearman rank correlation where convexity obtained higher correlations relative to nonconvexity. Isotonic regression results for all other cases are found in Appendix 1.

In conclusion, it seems that the specifications of technology have a larger impact on the Luenberger-Hicks-Moorsteen indicator than on the Luenberger indicator. Thus, for the

\footnotetext{
${ }^{10}$ Simar and Zelenyuk (2006) refine this Li (1996) test statistic for bounded distance functions. Two issues prevent considering these refinements in our context. First, some of the directional distance functions entering the Luenberger productivity indicator are unbounded. Then, the Simar and Zelenyuk (2006) procedure is identical to the $\mathrm{Li}$ (1996) test statistic. Second, for the bounded directional distance functions entering the Luenberger and Luenberger-Hicks-Moorsteen productivity indicator, it is unclear how one can apply this refinement either at the level of the distance functions (since each indicator has different component distance functions) or at the level of the productivity indicator itself (as differences of distance functions). This remains an open question so far.
} 
Luenberger-Hicks-Moorsteen indicator we would tend to give the largest weight to the TFP results obtained under the weakest possible axioms: nonconvex and VRS.

$<$ Figures 2 and 3 about here $>$

\section{Conclusions}

Using a balanced panel of agricultural data from 31 Chinese mainland provinces, this contribution is - to the best of our knowledge - the first to empirically illustrate and formally test for the differences between using either the Luenberger or the Luenberger-HicksMoorsteen productivity indicators. When computing these two frontier-based primal productivity indicators, the differences turn out to be significantly different for all four technology specifications. Thus, for our sample the Luenberger productivity indicator clearly does not maintain an TFP interpretation by approximation. Notice that these test statistics at the sample level may hide large differences for individual observations. Indeed, we observed regularly conflicting signs in productivity for individual observations: this problem is most pronounced under a flexible returns to scale specification.

The limitations of our study are quite clear: we have employed just one balanced panel data set to assess the differences and similarities between the Luenberger productivity indicator and the Luenberger-Hicks-Moorsteen TFP indicator. There is obviously a need to replicate this study on different data sets. Furthermore, future promising research areas may include the use of unbalanced in addition to balanced panel data (as in Kerstens and Van de Woestyne (2014)), as well as the use of parametric (as in Atkinson, Cornwell and Honerkamp (2003)) in addition to nonparametric specifications of technology to investigate the same research question.

Thus, one overall conclusion is that Luenberger and Luenberger-Hicks-Moorsteen productivity indicators empirically tend to measure somewhat different things. In case the interest centers on total factor productivity, then if one wants to be on the safe side it is probably wise to opt for the Luenberger-Hicks-Moorsteen productivity indicator. By contrast, if one contents oneself to measure local technical change (under the form of technical efficiency change and frontier change), then the Luenberger productivity indicator is an excellent choice. This conclusion confirms the empirical results from the earlier study of Kerstens and van de Woestyne (2014) regarding the Malmquist and Hicks-Moorsteen 
productivity indices: the Hicks-Moorsteen is the best choice of TFP index, the Malmquist is the technology index by excellence. This conclusion is important for practitioners: they should pick the right productivity index or indicator depending on their ultimate goals: either measuring total factor productivity, or measuring the local change of the technology.

\section{Acknowledgement}

Zhiyang Shen is grateful to the National Scholarship Study Abroad Program by the China Scholarship Council (No. 201308070020).

\section{References:}

Ang, F., P.J. Kerstens (2017) Decomposing the Luenberger-Hicks-Moorsteen Total Factor Productivity Indicator: An Application to U.S. Agriculture, European Journal of Operational Research, 260(1), 359-375.

Aparicio, J., J.T. Pastor, F. Vidal (2016) The Weighted Additive Distance Function, European Journal of Operational Research, 254(1), 338-346.

Atkinson, S., C. Cornwell, O. Honerkamp (2003) Measuring and Decomposing Productivity Change: Stochastic Distance Function Estimation Versus Data Envelopment Analysis, Journal of Business and Economic Statistics, 21(2), 284-294.

Azad, A.S., T. Ancev (2014) Measuring Environmental Efficiency of Agricultural Water Use: A Luenberger Environmental Indicator, Journal of Environmental Management, 145, 314-320.

Barros, C.P., E. Couto (2013) Productivity Analysis of European Airlines, 2000-2011, Journal of Air Transport Management, 31, 11-13.

Barros, C.P., G. Ferro, S. Managi, C.A. Romero (2008) A Comparison of the Luenberger and Luenberger-Hicks-Moorsteen Productivity Indicators Applied Argentinean Pension Funds: 1996-2007, Asociacion Argentina de Economia Politica (XLIII Reunión Anual).

Barros, C.P., A. Ibiwoye, S. Managi (2008) Productivity Change of Nigerian Insurance Companies: 1994-2005, African Development Review, 20(3), 505-528.

Barros, C.P., S. Managi (2014) Productivity Change of UK Airports, International Journal of Logistics Economics and Globalisation, 6(1), 22-41.

Bjurek, H. (1996) The Malmquist Total Factor Productivity Index, Scandinavian Journal of Economics, 98(2), 303-313.

Briec, W. (1997) A Graph-Type Extension of Farrell Technical Efficiency Measure, Journal of Productivity Analysis, 8(1), 95-110. 
Briec, W. (1998) Hölder Distance Function and Measurement of Technical Efficiency, Journal of Productivity Analysis, 11(2), 111-131.

Briec, W., K. Kerstens (2004) A Luenberger-Hicks-Moorsteen Productivity Indicator: Its Relation to the Hicks-Moorsteen Productivity Index and the Luenberger Productivity Indicator, Economic Theory, 23(4), 925-939.

Briec, W., K. Kerstens (2009a) The Luenberger Productivity Indicator: An Economic Specification Leading to Infeasibilities, Economic Modelling, 26(1), 597-600.

Briec, W., K. Kerstens (2009b) Infeasibilities and Directional Distance Functions: With Application to the Determinateness of the Luenberger Productivity Indicator, Journal of Optimization Theory and Applications, 141(1), 55-73.

Briec, W., K. Kerstens (2011) The Hicks-Moorsteen Productivity Index Satisfies the Determinateness Axiom, Manchester School, 79(4), 765-775.

Briec, W., K. Kerstens, and P. Vanden Eeckaut (2004) Non-convex Technologies and Cost Functions: Definitions, Duality and Nonparametric Tests of Convexity, Journal of Economics, 81(2), 155-192.

Caves, D., L. Christensen, W. Diewert (1982). The Economic Theory of Index Numbers and the Measurement of Inputs, Outputs and Productivity, Econometrica, 50(6), 13931414.

Chambers, R.G. (1998) Input and Output Indicators, in: R. Färe, S. Grosskopf, R. Russell (eds) Index Numbers: Essays in Honour of Sten Malmquist, Boston, Kluwer, 241-271.

Chambers, R.G. (2002) Exact Nonradial Input, Output, and Productivity Measurement, Economic Theory, 20(4), 751-765.

Chambers, R.G., R. Färe, S. Grosskopf (1996) Productivity Growth in APEC Countries, Pacific Economic Review, 1(3), 181-190.

Chen, P., M. Yu, C. Chang, S. Hsu (2008) Total Factor Productivity Growth in China's Agricultural Sector, China Economic Review, 19(4), 580-593.

Cherchye, L., T. Kuosmanen, T. Post (2001) FDH Directional Distance Functions with an Application to European Commercial Banks, Journal of Productivity Analysis, 15(3), 201-215.

Diewert, W.E. (2005) Index Number Theory Using Differences Rather Than Ratios, American Journal of Economics and Sociology, 64(1), 311-360.

Epure, M., K. Kerstens, D. Prior (2011) Bank Productivity and Performance Groups: A Decomposition Approach Based upon the Luenberger Productivity Indicator, European Journal of Operational Research, 211(3), 630-641.

Fan, Y., A. Ullah (1999) On Goodness-of-fit Tests for Weakly Dependent Processes using Kernel Method, Journal of Nonparametric Statistics, 11(1), 337-360.

Färe, R., S. Grosskopf, M. Norris, Z. Zhang (1994). Productivity Growth, Technical Progress, and Efficiency Change in Industrialized Countries, American Economic Review, 84(1), $66-83$. 
Färe, R., S. Grosskopf, P. Roos (1996) On Two Definitions of Productivity, Economics Letters, 53(3), 269-274.

Färe, R., S. Grosskopf, P. Roos (1998) Malmquist Productivity Indices: A Survey of Theory and Practice, in: R. Färe, S. Grosskopf, R. Russell (eds) Index Numbers: Essays in Honour of Sten Malmquist, Boston, Kluwer, 127-190.

Goncalves, O. (2013) Efficiency and Productivity of French Ski Resorts, Tourism Management, 36, 650-657.

Grosskopf, S. (2003) Some Remarks on Productivity and Its Decompositions, Journal of Productivity Analysis, 20(3), 459-474.

Hackman S.T. (2008) Production Economics: Integrating the Microeconomic and Engineering Perspectives, Berlin, Springer.

Hulten, C. (2001) Total Factor Productivity: A Short Biography, in: C. Hulten, E. Dean, M. Harper (Eds.) New Developments in Productivity Analysis, Chicago, University of Chicago Press, 1-47.

Ito J. (2010) Inter-regional Difference of Agricultural Productivity in China: Distinction between Biochemical and Machinery Technology, China Economic Review, 21(3), 394-410.

Juo, J.-C., T.-T. Fu, M.-M. Yu, Y.-H. Lin (2016) Non-Radial Profit Performance: An Application to Taiwanese Banks, Omega, 65, 111-121.

Kapelko, M., I.M. Horta, A.S. Camanho, A. Oude Lansink (2015) Measurement of InputSpecific Productivity Growth with an Application to the Construction Industry in Spain and Portugal, International Journal of Production Economics, 166, 64-71.

Kapelko, M., A. Oude Lansink, S.E. Stefanou (2015) Analyzing the Impact of Investment Spikes on Dynamic Productivity Growth, Omega, 54, 116-124.

Karian, Z.A., E.J. Dudewicz (2010) Handbook of Fitting Statistical Distributions with R, Boca Raton, CRC Press.

Kerstens, K., S. Managi (2012) Total Factor Productivity Growth and Convergence in the Petroleum Industry: Empirical Analysis Testing for Convexity, International Journal of Production Economics, 139(1), 196-206.

Kerstens, K., I. Van de Woestyne (2014) Comparing Malmquist and Hicks-Moorsteen Productivity Indices: Exploring the Impact of Unbalanced vs. Balanced Panel Data, European Journal of Operational Research, 233(3), 749-758.

Leleu, H. (2009) Mixing DEA and FDH Models Together, Journal of the Operational Research Society, 60(12), 1730-1737.

Li, Q. (1996) Nonparametric Testing of Closeness Between Two Unknown Distribution Functions, Econometric Reviews, 15(1), 261-274.

Luenberger, D.G. (1992) New Optimality Principles for Economic Efficiency and Equilibrium, Journal of Optimization Theory and Applications, 75(2), 221-264. 
Mahlberg, B., B.K. Sahoo (2011) Radial and Non-Radial Decomposition of Luenberger Productivity Indicator With an Illustrative Application, International Journal of Production Economics, 131, 721-726.

Managi, S. (2010) Productivity Measures and Effects from Subsidies and Trade: An Empirical Analysis for Japan's Forestry, Applied Economics, 42(30), 3871-3883.

Molinos-Senante, M., A. Maziotis, R. Sala-Garrido (2014) The Luenberger Productivity Indicator in the Water Industry: An Empirical Analysis for England and Wales, Utilities Policy, 30, 18-28.

National Bureau of Statistics of China (1998-2015) China Statistical Yearbook.

National Bureau of Statistics of China (2000-2015) China Rural Statistical Yearbook.

National Bureau of Statistics of China (2001-2014) China Statistical Yearbook for Regional Economy.

Nishimizu, M., J. Page (1982). Total Factor Productivity Growth, Technological Progress and Technical Efficiency Change: Dimensions of Productivity Change in Yugoslavia, 1965-1978, Economic Journal, 92(368), 920-936.

O'Donnell, C. (2012) An Aggregate Quantity-Price Framework for Measuring and Decomposing Productivity and Profitability Change, Journal of Productivity Analysis, 38(3), 255-272.

Peyrache, A. (2014) Hicks-Moorsteen versus Malmquist: A Connection by Means of a Radial Productivity Index, Journal of Productivity Analysis, 41(3), 435-442.

Silvapulle, M.J., P.K. Sen (2005) Constrained Statistical Inference: Inequality, Order, and Shape Restrictions, New York, Wiley

Simar, L., V. Zelenyuk (2006) On Testing Equality of Distributions of Technical Efficiency Scores, Econometric Reviews, 25(4), 497-522.

Wang, K., Y.-M. Wei (2016) Sources of Energy Productivity Change in China during 19972012: A Decomposition Analysis based on the Luenberger Productivity Indicator, Energy Economics, 54, 50-59. 
Table 1: Descriptive Statistics of Inputs and Output

\begin{tabular}{ccccccc}
\hline Variable & Unit & Mean & Std. Dev. & Min & Max & Trend \\
\hline Labor & $10^{4}$ persons & 1632.9 & 1256.3 & 97.5 & 4914.7 & $1.0 \%$ \\
Machinery & $10^{4} \mathrm{kw}$ & 2378.2 & 2518.3 & 77.5 & 13101.4 & $5.6 \%$ \\
Land & $10^{3}$ hectares & 5081.5 & 3543.6 & 196.1 & 14378.3 & $0.4 \%$ \\
Pesticide & $10^{4}$ tons & 4.9 & 4.3 & 0.04 & 19.9 & $2.8 \%$ \\
Fertilizer & $10^{4}$ tons & 159.1 & 133.5 & 2.5 & 705.8 & $2.6 \%$ \\
Gross Output & $10^{8}$ yuan & 1022.4 & 842.7 & 27.4 & 4268.2 & $4.1 \%$ \\
\hline
\end{tabular}

Table 2: Descriptive Statistics for Average Luenberger and Luenberger-Hicks-Moorsteen Productivity Changes

\begin{tabular}{|c|c|c|c|c|}
\hline & \multicolumn{2}{|c|}{ Luenberger } & \multicolumn{2}{|c|}{ Luenberger-Hicks-Moorsteen } \\
\hline & CRS & VRS & CRS & VRS \\
\hline \multicolumn{5}{|l|}{ Convex } \\
\hline Mean & 0.0098 & 0.0097 & 0.0394 & 0.0277 \\
\hline Std. Dev. & 0.0087 & 0.0142 & 0.0190 & 0.0189 \\
\hline Min. & -0.0135 & -0.0436 & 0.0066 & -0.0150 \\
\hline Max. & 0.0256 & 0.0332 & 0.0746 & 0.0605 \\
\hline Contradictory $^{*}$ & $2 / 31$ & $7 / 31$ & & \\
\hline \multicolumn{5}{|l|}{ Nonconvex } \\
\hline Mean & 0.0091 & -0.0113 & 0.0314 & 0.0130 \\
\hline Std. Dev. & 0.0085 & 0.0234 & 0.0174 & 0.0164 \\
\hline Min. & -0.0134 & -0.0612 & -0.0061 & -0.0226 \\
\hline Max. & 0.0219 & 0.0389 & 0.0625 & 0.0352 \\
\hline Contradictory & $4 / 31$ & $18 / 31$ & & \\
\hline
\end{tabular}


Table 3: Li (1996) Test Statistics, Kullback-Leibner Divergence and Spearman Rank Correlation Related to Technology Specifications

\begin{tabular}{|c|c|c|c|c|}
\hline & & & \multicolumn{2}{|c|}{ Luenberger vs. LHM } \\
\hline & & Li (1996) Test & KL Divergence & $\begin{array}{c}\text { Spearman rank } \\
\text { correlation }\end{array}$ \\
\hline \multirow[t]{2}{*}{ Convex } & CRS & $82.66^{* * *}$ & $0.54157 / 0.72060$ & 0.83116 \\
\hline & VRS & $35.41^{* * *}$ & $0.29458 / 0.38061$ & 0.77568 \\
\hline \multirow[t]{4}{*}{ Nonconvex } & CRS & $61.71^{* * *}$ & $0.40938 / 0.54593$ & 0.87229 \\
\hline & VRS & $43.83^{* * *}$ & $0.24344 / 0.27876$ & 0.64614 \\
\hline & & & \multicolumn{2}{|c|}{ CRS vs. VRS } \\
\hline & & Li (1996) Test & KL Divergence & $\begin{array}{c}\text { Spearman rank } \\
\text { correlation }\end{array}$ \\
\hline \multirow[t]{2}{*}{ Luenberger } & Convex & 0.48 & $0.01401 / 0.01638$ & 0.86453 \\
\hline & Nonconvex & $41.76^{* * *}$ & $0.26826 / 0.30041$ & 0.53247 \\
\hline \multirow[t]{4}{*}{ LHM } & Convex & $7.2^{* * *}$ & $0.03364 / 0.03453$ & 0.88312 \\
\hline & Nonconvex & $9.82^{* * *}$ & $0.23925 / 0.45560$ & 0.75552 \\
\hline & & \multicolumn{3}{|c|}{ Convex vs Nonconvex } \\
\hline & & Li (1996) Test & KL Divergence & $\begin{array}{c}\text { Spearman rank } \\
\text { correlation }\end{array}$ \\
\hline \multirow[t]{2}{*}{ Luenberger } & CRS & 0.27 & $0.00833 / 0.00932$ & 0.86974 \\
\hline & VRS & $43.11^{* * *}$ & $0.24509 / 0.26643$ & 0.62103 \\
\hline \multirow[t]{2}{*}{ LHM } & CRS & $1.73^{* *}$ & $0.01798 / 0.01816$ & 0.89891 \\
\hline & VRS & $2.47^{* * * *}$ & $0.03102 / 0.03153$ & 0.81005 \\
\hline
\end{tabular}

${ }^{\dagger}$ Li test: critical values at $1 \%$ level $=2.33 .(* * *) ; 5 \%$ level $=1.64(* *) ; 10 \%$ level $=1.28\left(^{*}\right)$. 
Table 4: Descriptive Statistics for Luenberger and Luenberger-Hicks-Moorsteen Productivity Changes Over Time Under a Convex VRS Technology

\begin{tabular}{|c|c|c|c|c|c|c|c|c|c|}
\hline \multirow[b]{2}{*}{ Year } & \multicolumn{4}{|c|}{ Luenberger } & \multicolumn{4}{|c|}{ Luenberger-Hicks-Moorsteen } & \multirow[b]{2}{*}{ Contradictory* } \\
\hline & Mean & Std. Dev & Min. & Max. & Mean & Std. Dev & Min. & Max. & \\
\hline $97-98$ & 0.0154 & 0.0381 & -0.0603 & 0.1055 & 0.0401 & 0.0942 & -0.1547 & 0.3108 & $2 / 31$ \\
\hline 98-99 & -0.0010 & 0.0413 & -0.0672 & 0.0874 & -0.0028 & 0.0989 & -0.2185 & 0.1638 & $1 / 31$ \\
\hline $99-00$ & 0.0019 & 0.0413 & -0.1262 & 0.0885 & 0.0142 & 0.0951 & -0.3153 & 0.1846 & $1 / 31$ \\
\hline 00-01 & 0.0113 & 0.0259 & -0.0432 & 0.0659 & 0.0311 & 0.0601 & -0.1896 & 0.1197 & $7 / 31$ \\
\hline 01-02 & 0.0127 & 0.0353 & -0.0837 & 0.0815 & 0.0452 & 0.0913 & -0.0799 & 0.3381 & $3 / 31$ \\
\hline 02-03 & 0.0014 & 0.0408 & -0.1173 & 0.0638 & 0.0065 & 0.0771 & -0.2954 & 0.0993 & $3 / 31$ \\
\hline 03-04 & 0.0203 & 0.0376 & -0.0760 & 0.0989 & 0.0572 & 0.0670 & -0.0863 & 0.2729 & $4 / 31$ \\
\hline 04-05 & -0.0017 & 0.0340 & -0.1284 & 0.0733 & 0.0022 & 0.0645 & -0.1967 & 0.1483 & $4 / 31$ \\
\hline $05-06$ & 0.0115 & 0.0374 & -0.1156 & 0.0654 & 0.0405 & 0.0638 & -0.1060 & 0.1418 & $3 / 31$ \\
\hline 06-07 & 0.0058 & 0.0296 & -0.0808 & 0.0773 & 0.0212 & 0.0581 & -0.0671 & 0.1894 & $2 / 31$ \\
\hline 07-08 & 0.0077 & 0.0225 & -0.0855 & 0.0460 & 0.0316 & 0.0507 & -0.0556 & 0.2120 & $8 / 31$ \\
\hline 08-09 & 0.0082 & 0.0319 & -0.0662 & 0.1359 & 0.0100 & 0.0441 & -0.1165 & 0.0735 & $2 / 31$ \\
\hline $09-10$ & 0.0077 & 0.0147 & -0.0351 & 0.0445 & 0.0252 & 0.0338 & -0.0517 & 0.0897 & $6 / 31$ \\
\hline $10-11$ & 0.0164 & 0.0199 & -0.0507 & 0.0441 & 0.0421 & 0.0381 & -0.0674 & 0.1346 & $1 / 31$ \\
\hline $11-12$ & 0.0140 & 0.0107 & -0.0052 & 0.0390 & 0.0339 & 0.0295 & -0.0223 & 0.1245 & $4 / 31$ \\
\hline $12-13$ & 0.0171 & 0.0237 & -0.0746 & 0.0869 & 0.0385 & 0.0318 & -0.0372 & 0.1074 & $1 / 31$ \\
\hline $13-14$ & 0.0171 & 0.0233 & -0.0324 & 0.1156 & 0.0346 & 0.0447 & -0.1654 & 0.0877 & $2 / 31$ \\
\hline
\end{tabular}

* Contradictory: opposite signs of average productivity change of Luenberger and Luenberger-Hicks-Moorsteen. 
Figure 1: Cumulative Luenberger and Luenberger-Hicks-Moorsteen Productivity Indicators for China

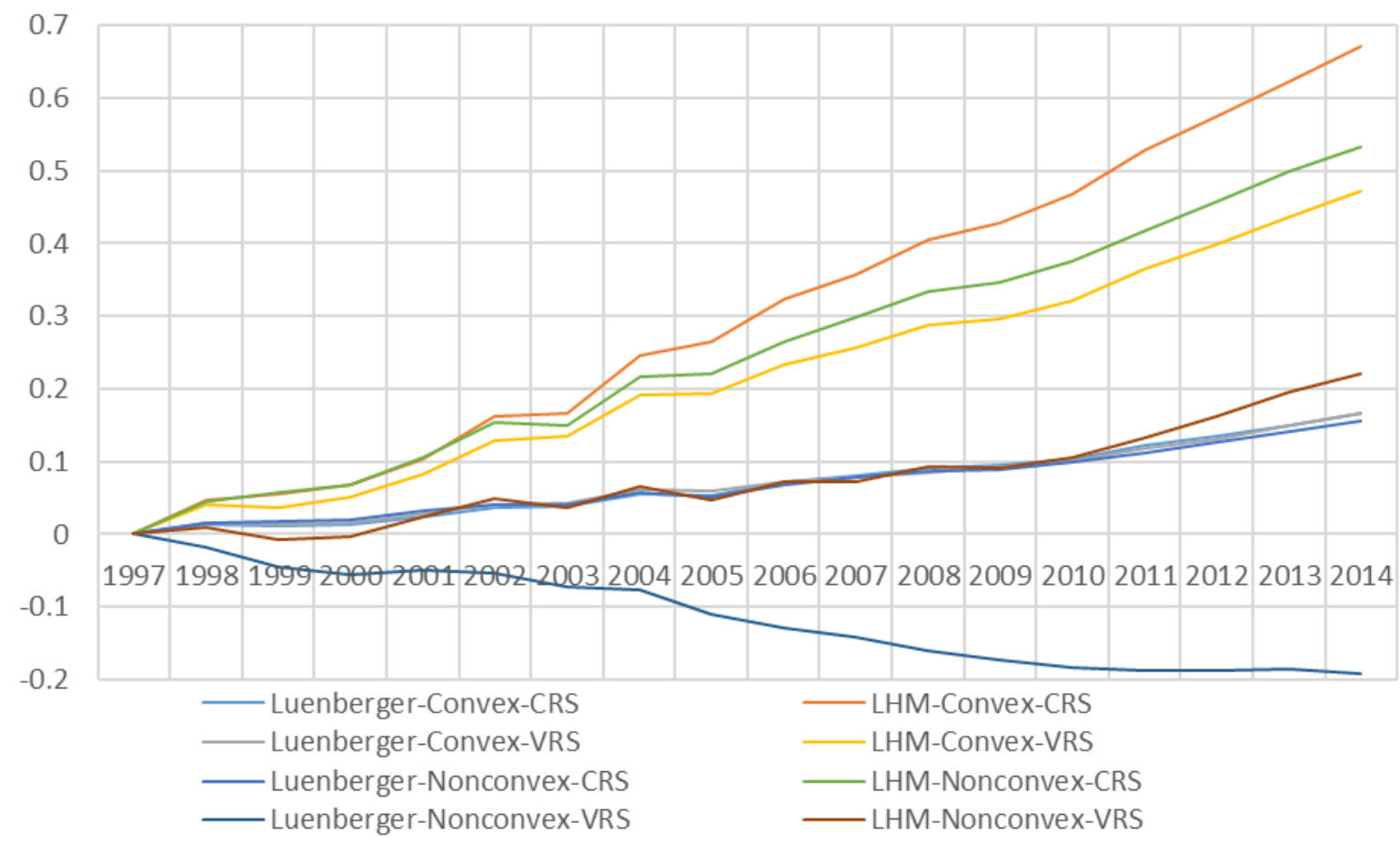


Figure 2: Isotonic Regression Between LHM under Convexity: CRS versus VRS

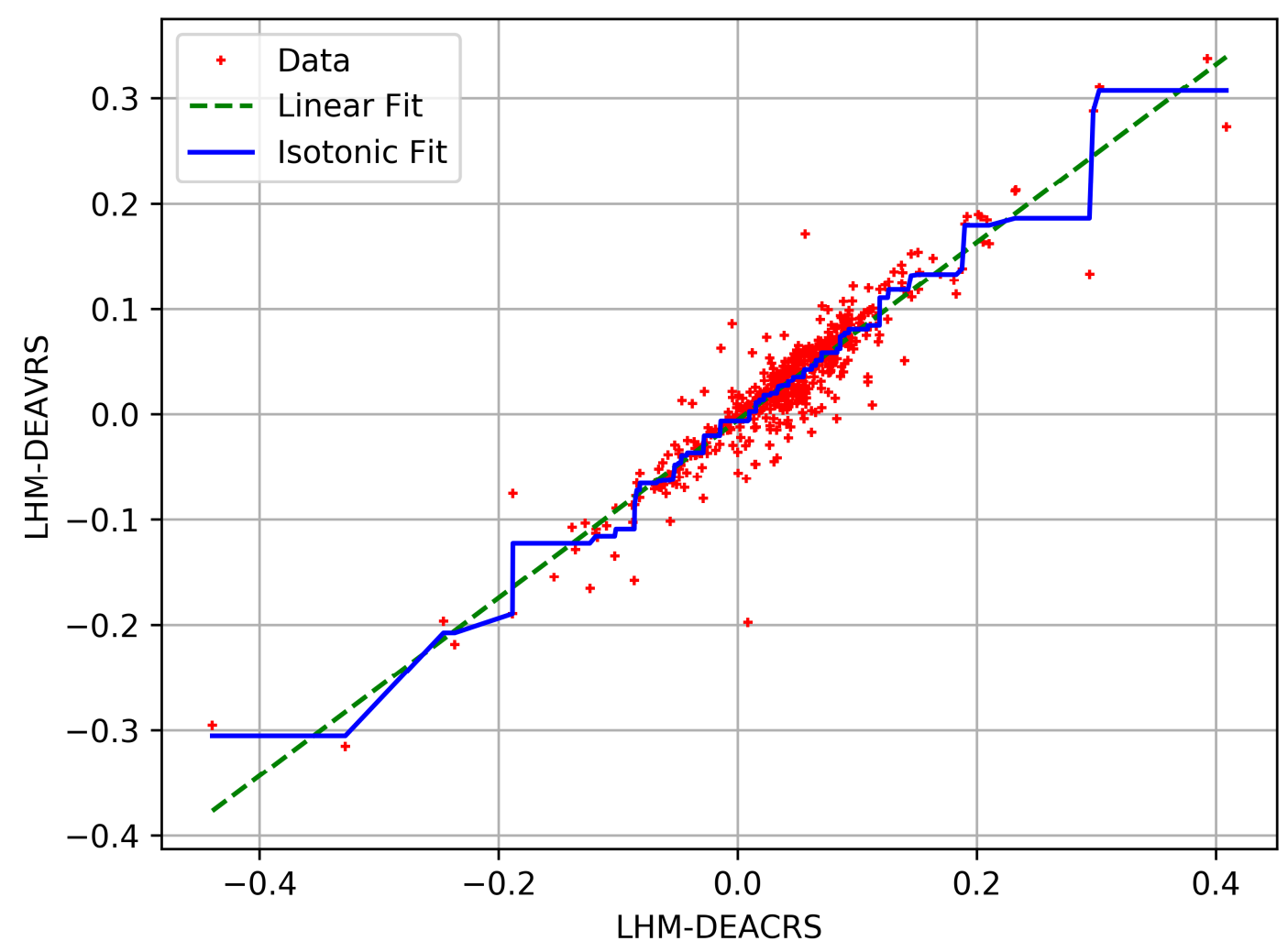


Figure 3: Isotonic Regression Between LHM under Nonconvexity: CRS versus VRS

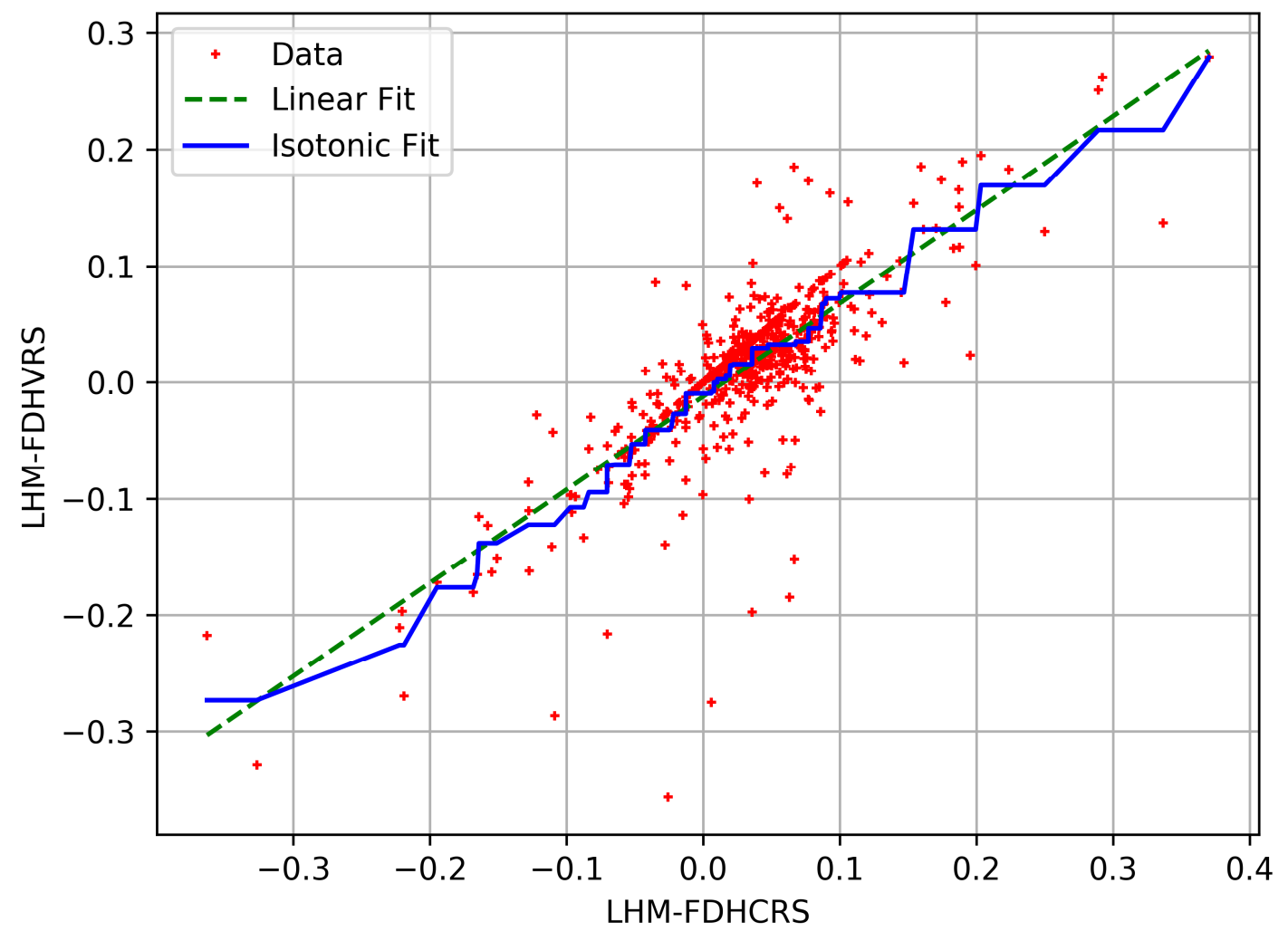

